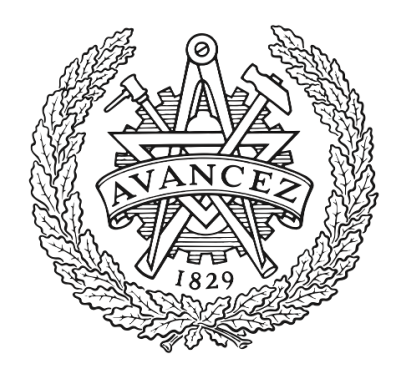

\title{
CHALMERS
}

UNIVERSITY OF TECHNOLOGY

\section{Methane oxidation over Pd supported on ceria-alumina under rich/lean cycling conditions}

Downloaded from: https://research.chalmers.se, 2023-04-26 13:15 UTC

Citation for the original published paper (version of record):

Fouladvand, S., Schernich, S., Libuda, J. et al (2013). Methane oxidation over Pd supported on ceria-alumina under rich/lean cycling conditions. Topics in Catalysis, 56(1-8): 410-415. http://dx.doi.org/10.1007/s11244-013-9988-2

N.B. When citing this work, cite the original published paper. 


\title{
Methane oxidation over Pd supported on ceria-alumina under rich/lean cycling conditions
}

\author{
Sheedeh Fouladvand ${ }^{1 *}$, Stefan Schernich ${ }^{2}$, Jörg Libuda ${ }^{2}$, Henrik Grönbeck ${ }^{1}$, Torben Pingel ${ }^{1}$, Eva \\ Olsson $^{l}$, Magnus Skoglundh ${ }^{1}$ and Per-Anders Carlsson ${ }^{1}$ \\ ${ }^{1}$ Competence Centre for Catalysis, Chalmers University of Technology, 41296 Göteborg, Sweden \\ ${ }^{2}$ Lehrstuhl für Physikalische Chemie II and Erlangen Catalysis Resource Center, University Erlangen- \\ Nuremberg, 91058 Erlangen, Germany
}

\begin{abstract}
Catalysts with highly dispersed palladium on alumina, alumina doped with $20 \mathrm{wt} .-\%$ ceria and ceria have been prepared, characterized and examined for net-lean methane oxidation. In particular, the activity and selectivity were investigated during rich/lean cycling of the feed. The ceria content is found to influence both the general and the instantaneous activity responses. The results indicate that the active phase of palladium changes between reduced and oxidised Pd during the rich/lean cycling, and that the process is influenced by the presence of ceria.
\end{abstract}

Keywords: Environmental catalysis; $\mathrm{CH}_{4}$ activation; low-temperature activity; selectivity y; $\mathrm{PdO}$

\section{Introduction}

Regulations imposed on pollutant emissions from automobiles led to the introduction and development of catalytic exhaust aftertreatment devices already in the 1970's. To decrease carbon dioxide emissions, attention has recently been directed towards combustion of fuels from biological feedstock, which are alternatives to fossil fuels. Combustion of natural gas and biogas, which primarily consist of methane, results in reduced emissions of, e.g. $\mathrm{CO}_{2}, \mathrm{NO}_{\mathrm{x}}$ and particulate matter, as compared to combustion of longer hydrocarbons. However, due to high green house potential, methane emissions should be minimized from the exhaust to be an environmentally appealing fuel [1]. Catalytic oxidation of methane is still a challenge, especially at low temperatures. Palladium is among the most active catalysts for methane oxidation $[2,3]$ and the addition of ceria to the catalyst has shown to further improve the activity [4]. Ceria is reported to enhance the noble metal dispersion and promote both oxidation and reduction of the metal phase during dynamic reaction conditions [4]. Moreover, the presence of ceria is known to enhance the activity for methane oxidation at low temperatures and to increase the selectivity to complete oxidation [5].

\footnotetext{
* Corresponding author.

E-mail address: sheedeh@chalmers.se (Sheedeh Fouladvand)
} 
In the present study, we investigate methane oxidation over supported palladium, addressing the effect of doping alumina with ceria. Catalysts with palladium on alumina, alumina doped with 20 wt. $\%$ ceria and ceria have been prepared, characterized and examined for net-lean methane oxidation. In particular, the activity and selectivity were investigated during rich/lean cycling of the feed.

\section{Experimental Section}

\section{Catalyst preparation and characterization}

Supported palladium catalysts with 2.2 wt.-\% Pd were prepared by incipient-wetness impregnation [6]. An amount of $230 \mathrm{mg}$ of either alumina (Sasol), alumina doped with $20 \mathrm{wt} \%$ of ceria (Sasol) or ceria (Rhône-Poulenc) was added to $114 \mathrm{mg}$ aqueous solution of tetraaminpalladium(II) nitrate (4.6 wt\% $\left(\mathrm{NH}_{3}\right)_{4} \mathrm{Pd}\left(\mathrm{NO}_{3}\right)_{2}$, Johnson Matthey), as the precursor for $\mathrm{Pd}$. The $\mathrm{pH}$ was adjusted to 11 by addition of diluted ammonia. The formed paste was mixed continuously for $15 \mathrm{~min}$ and then instantly frozen with liquid nitrogen and freeze-dried. The resulting powder was then calcined in air for $1 \mathrm{~h}$ at $550^{\circ} \mathrm{C}$, with a heating rate of $5^{\circ} \mathrm{C} / \mathrm{min}$ from room temperature to $550^{\circ} \mathrm{C}$.

Monolith samples were prepared by coating cordierite structures (Corning, $400 \mathrm{cpsi}, \mathrm{L}=15 \mathrm{~mm}$, $\varnothing=12 \mathrm{~mm}$ ) with $200 \mathrm{mg}$ of the respective catalyst powders through a dip-coating procedure using böhmite as a binder [7]. The samples were finally calcined in air at $600^{\circ} \mathrm{C}$ for $2 \mathrm{~h}$. Hereafter the ceriadoped sample is referred to as $\mathrm{Pd} / \mathrm{AlCe}-20$, where 20 indicates the wt.- $\%$ of ceria in alumina.

Characterization of the samples was performed using several experimental techniques. The total surface area of the powder and the monolith catalysts were measured by $\mathrm{N}_{2}$ physisorption at $77 \mathrm{~K}$ using a Micromeritics TriStar and Micromeritics ASAP 2010 instrument, respectively. The BET surface area was measured for both fresh powder samples and monolith catalysts before and after the activity/selectivity experiments. The support and Pd crystallite size of the fresh powder samples were investigated by X-ray diffraction (XRD) using a Bruker XRD D8 Advance instrument with monochromatic $\mathrm{CuK}_{\alpha 1}$ radiation, covering a $2 \theta$ range of $20-65.9^{\circ}$. The step size and the step time were $0.029^{\circ}$ and $1 \mathrm{~s}$, respectively. The sample rotation speed during the measurement was $60 \mathrm{rpm}$. Finally, transmission electron microscopy (TEM) was performed to image the Pd particle size of the fresh powder catalysts using a FEI Titan 80-300 TEM with a probe Cs (spherical abberation) corrector operated at $300 \mathrm{kV}$ and using a high angle annular dark field (HAADF) scanning TEM imaging mode providing $\mathrm{Z}$ number contrast. The electron probe size used for this study was about $0.2 \mathrm{~nm}$. 


\section{Catalyst evaluation}

The activity/selectivity experiments were performed in a continuous gas-flow reactor described in detail elsewhere [8]. Briefly, it consists of a quartz tube $(\mathrm{L}=500 \mathrm{~mm}, \varnothing=14 \mathrm{~mm})$, which is heated resistively by a surrounding metal coil insulated by a layer of glass wool. The temperature of the inlet gas $15 \mathrm{~mm}$ upstream the sample and the sample temperature were measured by individual thermocouples of $\mathrm{K}$ type. The inlet gas temperature was controlled by a PID regulator. Gases were introduced to the reactor by mass flow controllers (Brooks). The composition of the effluent stream was analyzed using a quadrupole mass spectrometer (Blazers Quadstar 422). To reduce axial temperature gradients, blank cordierite monoliths were positioned before and after the sample monolith [9]. Further, the reactor was insulated by quartz wool. All samples were pretreated in the reaction mixture of $0.1 \% \mathrm{CH}_{4}$ and $1.5 \% \mathrm{O}_{2}$, at $350^{\circ} \mathrm{C}$ for one hour using a total flow of $400 \mathrm{ml} / \mathrm{min}$, corresponding to a space velocity (GHSV) of $10000 \mathrm{~h}^{-1}$. The GHSV was kept constant during all experiments having Ar as the carrier gas. The rich/lean (RL) cycling experiment includes eight cycles at $350^{\circ} \mathrm{C}$ changing the oxygen concentration between $1.5 \%$ $(\mathrm{S}=7.5)$ and $0.05 \%(\mathrm{~S}=0.25)$. The duration of each cycle was 10 minutes, i.e. 5 minuets for each rich/lean phase.

\section{Results and Discussion}

The results from the BET surface area measurements are summarized in Table 1. The increase in surface area from the fresh powder to fresh monolith, specifically in the ceria containing samples, is likely due to the effect of the binder. The minor difference in the total surface area of the different catalysts before and after the activity/selectivity experiments signifies negligible sintering of the support material during the experiments. Thus, the following results may include reversible changes of the support phase only. Changes in the dispersed phase will be discussed more extensively below.

Table 1. BET surface area measured for the fresh powder sample and for the fresh and used monolith samples.

\begin{tabular}{lllllll}
\hline & Fresh powder & Fresh monolith & Used monolith & $\Delta$ BET surface \\
& sample $\left(\mathrm{m}^{2} / \mathrm{g}\right)$ & sample $\left(\mathrm{m}^{2} / \mathrm{g}\right)$ & sample $\left(\mathrm{m}^{2} / \mathrm{g}\right)$ & area $\left(\mathrm{m}^{2} / \mathrm{g}\right)$ \\
\hline $\mathrm{Pd} / \mathrm{Al}_{2} \mathrm{O}_{3}$ & 182 & 185 & 176 & -9 \\
$\mathrm{Pd} / \mathrm{AlCe}^{2} 20$ & 153 & 169 & 163 & -6 \\
$\mathrm{Pd} / \mathrm{CeO}_{2}$ & 94 & 128 & 123 & -5 \\
\hline
\end{tabular}


Further characterization of the powder catalysts was performed with XRD. In Fig. 1a, the diffractograms for the different catalysts as well as for the pure alumina and ceria supports are shown. The diffraction patterns observed for the catalysts originate mainly from the support phases. For example, the diffraction pattern for $\mathrm{Pd} / \mathrm{Al}_{2} \mathrm{O}_{3}$ with peaks at $2 \theta=37.5$ and $46^{\circ}$ is characteristic for $\gamma-\mathrm{Al}_{2} \mathrm{O}_{3}[10]$. Analogously, for the $\mathrm{Pd} / \mathrm{AlCe}-20$ and $\mathrm{Pd} / \mathrm{CeO}_{2}$ samples, diffraction peaks at $2 \theta=28.5,33.3,47,5$ and $56.4^{\circ}$ are characteristic for the fluorite structure of $\mathrm{CeO}_{2}[11,12]$. However, no peaks corresponding to Pd could be observed. This implies that the Pd particles are either not ordered and/or too small $(<2 \mathrm{~nm})$ to be distinguished from the other peaks [13].
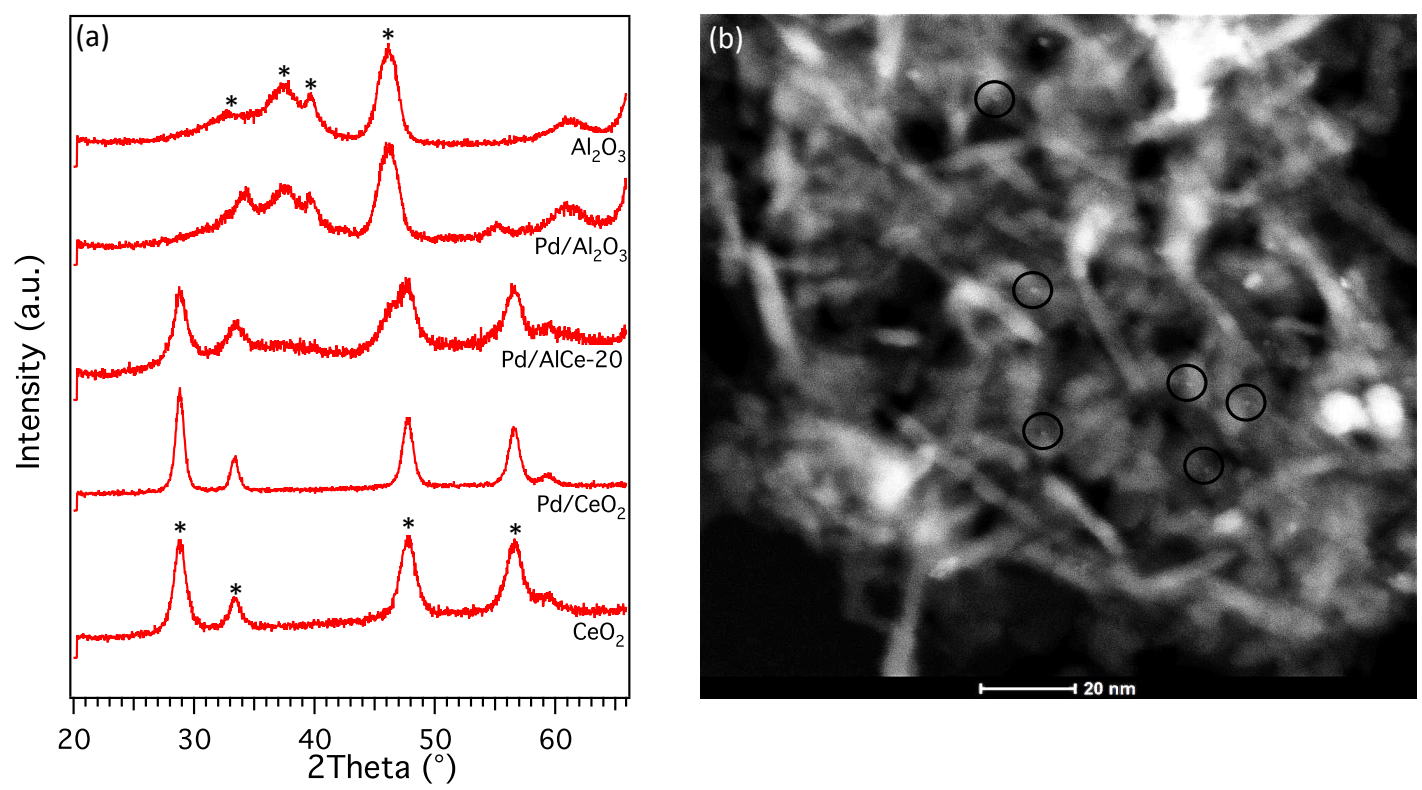

Fig. 1. (a) Normalized powder X-ray diffractograms of $\mathrm{Al}_{2} \mathrm{O}_{3}, \mathrm{Pd} / \mathrm{Al}_{2} \mathrm{O}_{3}, \mathrm{Pd} / \mathrm{AlCe}-20, \mathrm{Pd} / \mathrm{CeO}_{2}$ and $\mathrm{CeO}_{2}$ with step size $=0.029^{\circ}$, step time $=1 \mathrm{~s}$ and speed of sample rotation $=60 \mathrm{rpm}$ during the measurements. Characteristic diffraction lines of $\gamma-\mathrm{Al}_{2} \mathrm{O}_{3}$ and $\mathrm{CeO}_{2}$ are indicated by $\left({ }^{*}\right)$. (b) HAADF STEM image of the as prepared $2.2 \% \mathrm{Pd} / / \mathrm{Al}_{2} \mathrm{O}_{3}$ sample.

Fig. $1 \mathrm{~b}$ shows the HAADF STEM image of the as prepared $\mathrm{Pd} / \mathrm{Al}_{2} \mathrm{O}_{3}$ sample. Pd particles of subnanometer diameter are observable. Some, larger particles are also visible although the subnanometer sized particles are dominating. It is usually considered that noble metals interact more strongly with ceria than alumina. For example, ceria has been reported to promote high noble metal dispersion $[11,14]$. Thus, in the case of the $\mathrm{Pd} / \mathrm{AlCe}-20$ and $\mathrm{Pd} / \mathrm{CeO}_{2}$ samples, it is likely that $\mathrm{Pd}$ phase is at least as dispersed as for the $\mathrm{Pd} / \mathrm{Al}_{2} \mathrm{O}_{3}$ sample. The STEM result is consistent with that only the support phases could be observed with XRD. 
Fig. 2a-c shows the outlet reactor gas concentrations at $350^{\circ} \mathrm{C}$ from two successive $\mathrm{RL}$ cycles $\left(6^{\text {th }}\right.$ and $\left.7^{\text {th }}\right)$ with repeatable responses for $\mathrm{Pd} / \mathrm{Al}_{2} \mathrm{O}_{3}, \mathrm{Pd} / \mathrm{AlCe}-20$ and $\mathrm{Pd} / \mathrm{CeO}_{2}$, respectively. It is clear that both the stationary levels and the dynamic responses differ for the three catalysts. The average conversion of methane is lower for the rich periods (e.g., $t=81-86 \mathrm{~min}$ ) compared to the lean periods (e.g., $\mathrm{t}=86-91 \mathrm{~min}$ ), which is mainly due to oxygen deficiency during the rich periods. With increasing ceria content the activity for methane oxidation generally increases and the transient responses are more pronounced. Following the increase in conversion, the $\mathrm{CO}_{2}$ and $\mathrm{H}_{2}$ production also increase, whereas no considerable change in $\mathrm{CO}$ production is observed. The latter could be due to water-gas shift reactions promoted by ceria [15].
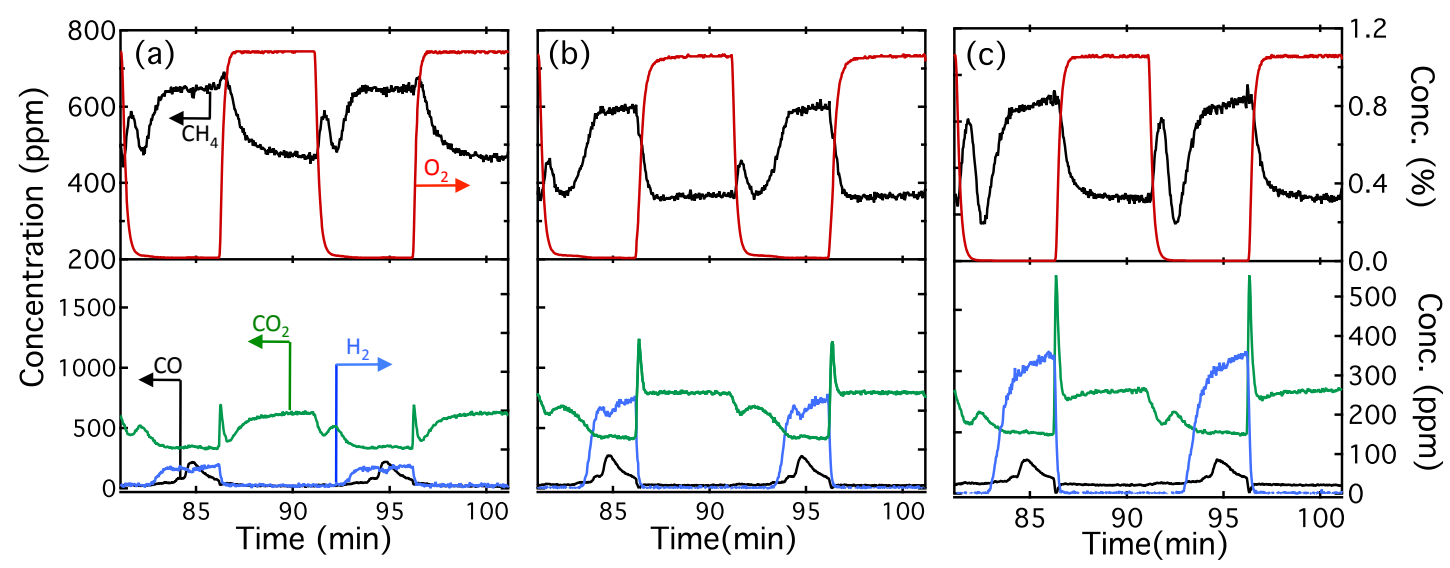

Fig. 2. Outlet reactor gas concentrations from oxidation of $0.1 \% \mathrm{CH}_{4}$ over $2.2 \%$ (a) $\mathrm{Pd} / \mathrm{Al}_{2} \mathrm{O}_{3}$ (b) $\mathrm{Pd} / \mathrm{AlCe}-20$ and (c) $\mathrm{Pd} / \mathrm{CeO}_{2}$ catalysts while periodically varying the oxygen concentration between $0.05 \%(\mathrm{~S}=0.25)$ for $5 \mathrm{~min}$ and $1.5 \%(\mathrm{~S}=7.5)$ for $5 \mathrm{~min}$ at $350^{\circ} \mathrm{C}$.

During the lean phases, the conversion increases with time. The catalyst behavior during the rich phases is more complicated. The conversion drops and rises rapidly in the beginning and then follows a descending trend with the time on stream. Finally, for the $\mathrm{Pd} / \mathrm{Al}_{2} \mathrm{O}_{3}$ sample a slight decrease in conversion at the introduction of the oxygen $(\mathrm{t}=85.5 \mathrm{~min})$ can be observed. The conversion recovers thereafter as the oxygen concentration approaches the stoichiometric ratio. The samples maximum temperature change at the lean/rich and rich/lean switches was measured to be less than $5^{\circ} \mathrm{C}$. This small change is not expected to have a significant influence on the methane oxidation. Thus, the activity is clearly influenced by the reactant stoichiometry, for which oxygen is the limiting reactant during rich conditions. In addition the observations can be discussed in terms of changes of the active phase, i.e., reduction and oxidation of Pd clusters, during the RL cycling, and how these processes are influenced by the support. 
Ferri et al. reported that palladium oxide is the active phase for methane oxidation at low temperatures $[16,17]$ in contrast to Hicks et al. $[18]$ proposing metallic $\mathrm{Pd}$ as the active phase for methane combustion. However there is still no consensus in the literature on the active phase of palladium for methane oxidation. Some studies emphasize the presence of both Pd and PdO phases [19, 20] or a thin PdO layer on metallic Pd [21] as to achieve high conversion. In addition, Choudhary et al. [22] differentiate between the activity of a partially reduced $\mathrm{PdO} / \mathrm{Al}_{2} \mathrm{O}_{3}$ catalyst and a partially oxidized $\mathrm{Pd}^{0} / \mathrm{Al}_{2} \mathrm{O}_{3}$ sample with the same $\mathrm{PdO}$ content. They considered the $\mathrm{PdO}$ formation pathway to influence the activity for methane combustion resulting in the superior performance of the partially oxidized $\mathrm{Pd}^{0} / \mathrm{Al}_{2} \mathrm{O}_{3}$ catalyst. Recent detailed work on Pd single crystals report that high activity for methane oxidation is achieved for under-coordinated Pd in epitaxial PdO(101) or metallic surface [23] whereas for non-ordered palladium oxides the activity is low.

In the present study we cannot unambiguously state which form of Pd is the most active phase. However, based on the transient responses we can reason as follows. During the lean phase, the conversion reaches fairly high values, which may be attributed to methane oxidation on deeply oxidised $\mathrm{Pd}\left(\mathrm{PdO}_{\mathrm{x}}, \mathrm{x}=>1\right)$, which thus should be considered as highly active. The rapid changes in methane conversion at the introduction of the rich phase can be discussed in terms of reduction of oxidised Pd by methane. As the oxygen concentration of the feed is lowered at the introduction of the rich period, the oxygen concentration drops in the reactor and the methane conversion decreases. This decrease could be due to both the change of reactant stoichiometry which is limited by the availability of oxygen and/or due to a reduction of the $\mathrm{PdO}_{\mathrm{x}}$ phase becoming less active. Upon time on stream, further reduction of $\mathrm{PdO}_{\mathrm{x}}$ leads to the formation of a sufficiently high number of $\mathrm{Pd}^{0}$ sites, which have a high activity for methane oxidation [23], explaining the temporal increase in methane conversion at $\mathrm{t}=92 \mathrm{~min}$. Evidently, thereafter, the available oxygen in the feed limits the methane oxidation. This is supported by the fact that observed methane conversion equals the expected conversion for complete consumption of supplied oxygen and that no oxygen could be detected in the effluent stream. Thus the present results can be interpreted such that fully oxidized or reduced Pd clusters facilitate methane oxidation while intermediate oxidation states suppress the oxidation of methane. Furthermore, the results from Kinnuen et al. [24] indicate that $\mathrm{Pd} / \mathrm{PdO}$ interface sites enhance methane oxidation through a new pathway for the $\mathrm{C}-\mathrm{H}$ bond dissociation. This supports the studies [25-27] finding the simultaneous presence of oxidized and reduced Pd phases necessary for high activity for methane conversion. Pd/PdO has also been reported by Pfefferle 
[28] to serve as a porthole for dissociation of gas phase and migration to the oxide support and subsequent exchange with oxygen from the oxide support. This provides the opportunity for the oxygen bonded to the support to take part in the reaction, favouring methane oxidation [29].

Burch et al. consider the inhibiting effect of water and carbon dioxide as to be important at temperatures below $450^{\circ} \mathrm{C}$ [30]. Formation of $\mathrm{Pd}(\mathrm{OH})_{2}$ blocks the effective access of methane to the active $\mathrm{PdO}$ sites. Card at al. [31] reported that $\mathrm{Pd}(\mathrm{OH})_{2}$ decomposes at temperatures exceeding $250^{\circ} \mathrm{C}$ but Cullis et al. [32] discussed the stabilization of the $\mathrm{Pd}(\mathrm{OH})_{2}$ phase by the ability of alumina to retain water. No inhibitory effect of water has been observed for Pd in metallic form [33]. In these studies water was included in the feed, whereas here water is only formed as a reaction product. Thus, the inhibitory effect of water is likely negligible in the present study.

Ceria is known to store and release oxygen due to the ability of cerium to easily change oxidation state between $\mathrm{Ce}^{3+}$ and $\mathrm{Ce}^{4+}$. Based on the aforementioned discussion, this phenomenon will likely influence the transient responses of the catalysts. For example at the introduction of the rich period, oxygen supplied form the support phase can be used for oxidation of methane on the Pd clusters through reversed spill-over processes. By increasing the amount of ceria in the support, the corresponding increase in amount of oxygen that can be stored/released is achieved. This likely explains the more pronounced transient effects with increasing amounts of ceria. However, also the methane conversion during lean conditions increases with increasing ceria content of the support. This cannot be explained by oxygen storage/release dynamics, which can facilitate transient effects only. Instead it seems that including ceria introduces other sites, which are more active. For example this can be due to that the $\mathrm{Pd}$ clusters are stabilised differently by ceria as compared to alumina and, thereby, expose more active sites. Another explanation could be that sites at the Pd-support boundary are of special importance. For example, it has been proposed that Pd-Ce interface sites are more active than the palladium sites. Also cerium interacts synergistically with palladium favoring methane oxidation at low temperatures $[5,11]$. Our results seem to support this idea as the number of Pd-Ce sites increases with increasing ceria content of the catalyst. In addition, these sites likely facilitate the transport of surface species between the support and the noble metal [34]. Besides, the maximum conversion during the rich phases is higher in the case of $\mathrm{Pd} / \mathrm{CeO}_{2}$ compared to the other two catalysts, which is explained by the capacity of ceria to provide mobile oxygen for the reaction. 
In summary we have investigated the oxidation of methane over highly dispersed Pd on alumina, alumina doped with 20 wt.- $\%$ ceria and ceria. It has been shown that the transient behavior, i.e., methane oxidation as a function of dynamic inlet gas conditions, involves complex oxidation and reduction processes that directly influence the global activity/selectivity. Also, it has been shown that the inclusion of ceria into alumina based catalyst formulations significantly can increase the performance of the catalyst.

\section{Acknowledgements}

This study has been performed at the Competence Centre for Catalysis, which is hosted by Chalmers University of Technology and financially supported by the Swedish Energy Agency and the member companies AB Volvo, Volvo Car Corporation, Scania CV AB, Haldor Topsøe A/S, and ECAPS AB. The authors acknowledge support by the DAAD (Deutscher Akademischer Austauschdienst) and by the COST Action CM1104. J.L. and St.S. acknowledge additional financial support by the Deutsche Forschungsgemeinschaft, including the Excellence Cluster "Engineering of Advanced Materials" in the framework of the excellence initiative. St.S. gratefully acknowledges a PhD grant of the "Fonds der Chemischen Industrie".

\section{References:}

1. Ciuparu D, Lyubovsky MR, Altman E, Pfefferle LD, Datye A (2002) Catalytic combustion of methane over palladium-based catalysts. Catalysis Reviews 44 (4):593-649. doi:10.1081/cr-120015482

2. Carstens JN, Su SC, Bell AT (1998) Factors Affecting the Catalytic Activity of Pd/ZrO2for the Combustion of Methane. Journal of Catalysis 176 (1):136-142

3. Carlsson P-A, Fridell E, Skoglundh M (2007) Metahne oxidation over Pt/Al2O3 and Pd/Al2O3 catalysts under transient conditions. Catalysis Letters 115 (1):1-7. doi:10.1007/s10562-007-9057-1

4. Trovarelli A, de Leitenburg C, Boaro M, Dolcetti G (1999) The utilization of ceria in industrial catalysis. Catalysis Today 50 (2):353-367

5. Haneda M, Mizushima T, Kakuta N (1998) Synergistic Effect between Pd and Nonstoichiometric Cerium Oxide for Oxygen Activation in Methane Oxidation. The Journal of Physical Chemistry B 102 (34):6579-6587. doi:10.1021/jp9819285

6. Becker E, Carlsson P-A, Skoglundh M (2009) Methane Oxidation over Alumina and Ceria Supported Platinum. Topics in Catalysis 52 (13):1957-1961. doi:10.1007/s11244-009-9379-x

7. Dawody J, Eurenius L, Abdulhamid H, Skoglundh M, Olsson E, Fridell E (2005) Platinum dispersion measurements for $\mathrm{Pt} / \mathrm{BaO} / \mathrm{Al} 2 \mathrm{O} 3$, NOx storage catalysts. Applied Catalysis A: General 296 (2):157-168 8. Lundgren S, Keck KE, Kasemo B (1994) A flow reactor system for catalytic reaction studies, allowing time- and space-resolved measurements of gas composition and temperature around the catalyst. Review of Scientific Instruments 65 (8):2696-2703

9. Wang-Hansen C, Kamp CJ, Skoglundh M, Andersson B, Carlsson P-A Experimental Method for Kinetic Studies of Gas-Solid Reactions: Oxidation of Carbonaceous Matter. The Journal of Physical Chemistry C 115 (32):16098-16108. doi:10.1021/jp204539g

10. Faria WLS, Perez CAC, Cesar DV, Dieguez LdC, Schmal M (2009) In situ characterizations of $\mathrm{Pd} / \mathrm{Al} 2 \mathrm{O} 3$ and $\mathrm{Pd} / \mathrm{CeO} 2 / \mathrm{Al} 2 \mathrm{O} 3$ catalysts for oxidative steam reforming of propane. Applied Catalysis B: Environmental 92 (1-2):217-224 
11. Ramirez-Lopez R, Elizalde-Martinez I, Balderas-Tapia L (2010) Complete catalytic oxidation of methane over Pd/CeO2-Al2O3: The influence of different ceria loading. Catalysis Today 150 (3-4):358362

12. Santos ACSF, Damyanova S, Teixeira GNR, Mattos LV, Noronha FB, Passos FB, Bueno JMC (2005) The effect of ceria content on the performance of $\mathrm{Pt} / \mathrm{CeO} 2 / \mathrm{A} 12 \mathrm{O} 3$ catalysts in the partial oxidation of methane. Applied Catalysis A: General 290 (1-2):123-132

13. Anderson JR PK (1985) Introduction to characterization and testing of catalysts. Academic Press Australia,

14. Kapar J, Fornasiero P, Graziani M (1999) Use of CeO2-based oxides in the three-way catalysis. Catalysis Today 50 (2):285-298

15. Barbier Jr J, Duprez D (1994) Steam effects in three-way catalysis. Applied Catalysis B: Environmental 4 (2-3):105-140

16. Matam SK, Aguirre MH, Weidenkaff A, Ferri D Revisiting the Problem of Active Sites for Methane Combustion on Pd/A12O3 by Operando XANES in a Lab-Scale Fixed-Bed Reactor. The Journal of Physical Chemistry C 114 (20):9439-9443. doi:10.1021/jp1019697

17. Santhosh Kumar M, Eyssler A, Hug P, van Vegten N, Baiker A, Weidenkaff A, Ferri D (2010) Elucidation of structure, activity relationships of model three way catalysts for the combustion of methane. Applied Catalysis B: Environmental 94 (1-2):77-84

18. Hicks RF, Qi H, Young ML, Lee RG (1990) Structure sensitivity of methane oxidation over platinum and palladium. Journal of Catalysis 122 (2):280-294

19. Fujimoto K-i, Ribeiro FH, Avalos-Borja M, Iglesia E (1998) Structure and Reactivity of $\mathrm{PdOx} / \mathrm{ZrO} 2$ Catalysts for Methane Oxidation at Low Temperatures. Journal of Catalysis 179 (2):431-442 20. Su SC, Carstens JN, Bell AT (1998) A Study of the Dynamics of Pd Oxidation and PdO Reduction by H2and CH4. Journal of Catalysis 176 (1):125-135

21. Burch R, Urbano FJ (1995) Investigation of the active state of supported palladium catalysts in the combustion of methane. Applied Catalysis A: General 124 (1):121-138

22. Choudhary TV, Banerjee S, Choudhary VR (2005) Influence of PdO content and pathway of its formation on methane combustion activity. Catalysis Communications 6 (2):97-100

23. Hellman A, Resta A, Martin NM, Gustafson J, Trinchero A, Carlsson PA, Balmes O, Felici R, van Rijn R, Frenken JWM, Andersen JN, Lundgren E, Grönbeck H The Active Phase of Palladium during Methane Oxidation. The Journal of Physical Chemistry Letters 3 (6):678-682. doi:10.1021/jz300069s

24. Kinnunen NM, Hirvi JT, Suvanto M, Pakkanen TA Role of the Interface between Pd and PdO in Methane Dissociation. The Journal of Physical Chemistry C 115 (39):19197-19202. doi:10.1021/jp204360c

25. Kinnunen NM, Hirvi JT, Ven $\sqrt{\S} 1 \sqrt{ }$ \&inen T, Suvanto M, Pakkanen TA Procedure to tailor activity of methane combustion catalyst: Relation between $\mathrm{Pd} / \mathrm{PdOx}$ active sites and methane oxidation activity. Applied Catalysis A: General 397 (1-2):54-61

26. Thevenin PO, Pocoroba E, Pettersson LJ, Karhu H, Väyrynen IJ, Järös SG (2002) Characterization and Activity of Supported Palladium Combustion Catalysts. Journal of Catalysis 207 (1):139-149

27. Yazawa Y, Yoshida H, Takagi N, Komai S-i, Satsuma A, Hattori T (1998) Oxidation state of palladium as a factor controlling catalytic activity of $\mathrm{Pd} / \mathrm{SiO} 2-\mathrm{A} 2 \mathrm{O} 3$ in propane combustion. Applied Catalysis B: Environmental 19 (3-4):261-266

28. Schwartz WR, Pfefferle LD Combustion of Methane over Palladium-Based Catalysts: Support Interactions. The Journal of Physical Chemistry C 116 (15):8571-8578. doi:10.1021/jp2119668

29. Ciuparu D, Bozon-Verduraz F, Pfefferle L (2002) Oxygen Exchange between Palladium and Oxide Supports in Combustion Catalysts. The Journal of Physical Chemistry B 106 (13):3434-3442. doi:10.1021/jp013577r

30. Burch R, Urbano FJ, Loader PK (1995) Methane combustion over palladium catalysts: The effect of carbon dioxide and water on activity. Applied Catalysis A: General 123 (1):173-184

31. Card RJ, Schmitt JL, Simpson JM (1983) Palladium-carbon hydrogenolysis catalysts: The effect of preparation variables on catalytic activity. Journal of Catalysis 79 (1):13-20

32. Cullis CF, Nevell TG, Trimm DL (1972) Role of the catalyst support in the oxidation of methane over palladium. Journal of the Chemical Society, Faraday Transactions 1: Physical Chemistry in Condensed Phases 68:1406-1412

33. Ciuparu D, Pfefferle L (2001) Support and water effects on palladium based methane combustion catalysts. Applied Catalysis A: General 209 (1-2):415-428

34. Carlsson P-A, Skoglundh M (2011) Low-temperature oxidation of carbon monoxide and methane over alumina and ceria supported platinum catalysts. Applied Catalysis B: Environmental 101 (3-4):669675 
